\title{
BMJ
}

\section{Effect of calcium supplements on risk of myocardial infarction and cardiovascular events: meta-analysis}

\author{
Mark J Bolland, senior research fellow, ${ }^{1}$ Alison Avenell, clinical senior lecturer, ${ }^{2}$ John A Baron, professor, ${ }^{3}$ \\ Andrew Grey, associate professor, ${ }^{1}$ Graeme S MacLennan, senior research fellow, ${ }^{2}$ Greg D Gamble, research \\ fellow, ${ }^{1}$ lan R Reid, professor ${ }^{1}$
}

${ }^{1}$ Department of Medicine, Faculty of Medical and Health Sciences,

University of Auckland, Private Bas 92 019, Auckland 1142, New Zealand

${ }^{2}$ Health Services Research Unit, University of Aberdeen

${ }^{3}$ Department of Medicine, and Department of Community and Family Medicine, Dartmouth Medical School, NH, USA

Correspondence to: I R Reid i.reid@auckland.ac.nz

Cite this as: $B M J$ I 2010;341:C3691 doi:10.1136/bmi.c3691

\section{ABSTRACT}

Objective To investigate whether calcium supplements increase the risk of cardiovascular events.

Design Patient level and trial level meta-analyses.

Data sources Medline, Embase, and Cochrane Central Register of Controlled Trials (1966-March 2010), reference lists of meta-analyses of calcium supplements, and two clinical trial registries. Initial searches were carried out in November 2007, with electronic database searches repeated in March 2010.

Study selection Eligible studies were randomised, placebo controlled trials of calcium supplements ( $\geq 500 \mathrm{mg} /$ day), with 100 or more participants of mean age more than 40 years and study duration more than one year. The lead authors of eligible trials supplied data. Cardiovascular outcomes were obtained from self reports, hospital admissions, and death certificates.

Results 15 trials were eligible for inclusion, five with patient level data (8151 participants, median follow-up 3.6 years, interquartile range 2.7-4.3 years) and 11 with trial level data (11921 participants, mean duration 4.0 years). In the five studies contributing patient level data, 143 people allocated to calcium had a myocardial infarction compared with 111 allocated to placebo (hazard ratio 1.31, 95\% confidence interval 1.02 to 1.67 , $\mathrm{P}=0.035)$. Non-significant increases occurred in the incidence of stroke (1.20, 0.96 to $1.50, P=0.11)$, the composite end point of myocardial infarction, stroke, or sudden death $(1.18,1.00$ to $1.39, P=0.057)$, and death $(1.09,0.96$ to $1.23, \mathrm{P}=0.18)$. The meta-analysis of trial level data showed similar results: 296 people had a myocardial infarction (166 allocated to calcium, 130 to placebo), with an increased incidence of myocardial infarction in those allocated to calcium (pooled relative risk $1.27,95 \%$ confidence interval 1.01 to 1.59 , $\mathrm{P}=0.038$ ).

Conclusions Calcium supplements (without coadministered vitamin D) are associated with an increased risk of myocardial infarction. As calcium supplements are widely used these modest increases in risk of cardiovascular disease might translate into a large burden of disease in the population. A reassessment of the role of calcium supplements in the management of osteoporosis is warranted.

\section{INTRODUCTION}

Osteoporosis is a major cause of morbidity and mortality in older people. ${ }^{1}$ Calcium supplements marginally reduce the risk of fracture, ${ }^{23}$ and most guidelines recommend adequate calcium intake as an integral part of the prevention or treatment of osteoporosis. ${ }^{45}$ Consequently, calcium supplements are commonly used by people over the age of 50 . Observational studies suggest that high calcium intake might protect against vascular disease, ${ }^{6-8}$ and the findings are consistent with those of interventional studies of calcium supplements that show improvement in some vascular risk factors. ${ }^{9-11}$ In contrast, calcium supplements accelerate vascular calcification and increase mortality in patients with renal failure, in both dialysis and predialysis populations. ${ }^{12-14}$ Furthermore, a five year randomised controlled trial of calcium supplements in healthy older women, in which cardiovascular events were prespecified as secondary end points, recently reported possible increases in rates of myocardial infarction and cardiovascular events in women allocated to calcium. ${ }^{1516}$ We carried out a meta-analysis of cardiovascular events in randomised trials of calcium supplements.

\section{METHODS}

In November 2007 we searched Medline, Embase, and the Cochrane Central Register of Controlled Trials for randomised placebo controlled trials of calcium supplements, using the terms "calcium", "randomised controlled trial", and "placebo" as text words, and corresponding MeSH terms (full details are available from the authors). We searched for studies in the reference lists of meta-analyses published between 1990 and 2007 of the effect of calcium supplements on bone density, fracture, colorectal neoplasia, and blood pressure, and in two clinical trial registries (ClinicalTrials.gov and Australian New Zealand Clinical Trials Registry). No language restrictions were applied. In March 2010 we updated the searches of the electronic databases (Medline: January 1966-March 2010, Embase: January 1980-March 2010, Central Register of Controlled Trials: first quarter 2010). 


\section{Study selection}

We included studies if they were randomised, double blind, placebo controlled trials; elemental calcium was administered at a dose of $\geq 500 \mathrm{mg} /$ day; the participants' mean age at baseline was more than 40 years; 100 or more participants were randomised; participants of either sex were studied; and the trial duration was more than one year.

We excluded trials concerning calcium and vitamin $\mathrm{D}$ given together with a placebo comparator (trials were only eligible if vitamin $\mathrm{D}$ was given to both intervention and control groups, because vitamin $\mathrm{D}$ supplementation has been associated with decreased mortality ${ }^{17}$ ); trials in which calcium was administered in the form of dietary modification or a complex nutritional supplement; and trials in which most participants had a major systemic disease other than osteoporosis.

\section{Search results}

One investigator $(\mathrm{MB})$ carried out the initial search and two investigators (AG and $\mathrm{MB}$ ) independently reviewed all potentially relevant studies. Overall, 190 potentially relevant reports of studies were identified from the initial searches, but only 15 studies were eligible for analysis. ${ }^{151618-33}$ Thirteen studies compared calcium supplements with placebo, ${ }^{151618-272931-33}$ one study had a $2 \times 2$ factorial design allowing comparison of calcium with placebo and calcium plus vitamin D with vitamin $\mathrm{D},{ }^{28}$ and one study compared calcium plus alendronate with alendronate. ${ }^{30}$

\section{Data description}

We invited the lead author of each eligible study to provide patient level data on cardiovascular events that occurred during the study irrespective of whether the participant was still taking the trial drug. When such data were not available we requested summary data at trial level. We obtained patient level data on cardiovascular outcomes for five studies, and partially complete trial level data for six. No data were available for four studies because the original records were no longer available and cardiovascular events were not

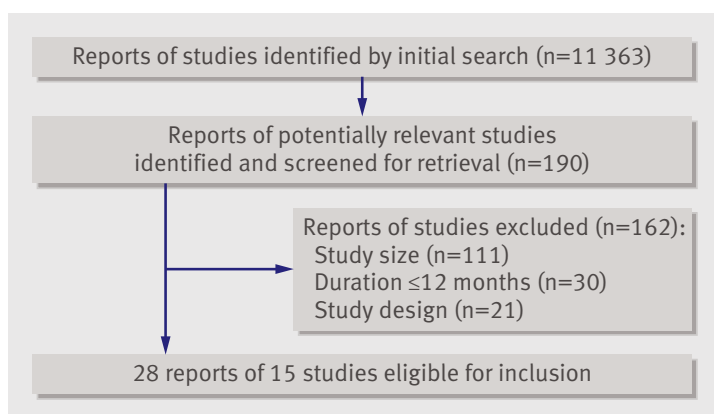

Fig 1| Flowchart of studies. Initial search was in November 2007: 9358 reports were identified, 173 reports of potentially relevant studies retrieved, 150 reports excluded, and 23 reports of 15 individual studies identified. Search was updated in March 2010: a further 2005 reports were identified and 17 reports retrieved but no new studies identified previously reported, ${ }^{1820}$ or no cardiovascular data were available. ${ }^{2326}$ Thus, patient level data on cardiovascular outcomes were available for $63 \%$ of participants in the 15 eligible studies, complete trial level data for $85 \%$ of participants, and at least partially complete trial level data for $93 \%$ of participants. Basic demographic and other trial related data were either supplied by the lead authors (or nominated deputies) or extracted from the original publication by an investigator $(\mathrm{MB})$.

\section{Ascertainment of cardiovascular events}

We considered a myocardial infarction to have occurred when either of the terms "myocardial infarction" or "heart attack", or code 410 (international classification of diseases, ninth revision), was used to describe the event. A stroke was considered to have occurred when any of the terms "stroke", "cerebral infarction", "intracerebral hemorrhage", "subarachnoid hemorrhage", or "cerebrovascular accident", or any of the ICD-9 codes 430, 431, 433, 434 were used to describe the event. We considered a sudden death to have occurred when the term "sudden death" or the ICD-9 code 798 was used to describe the event.

Five studies contributed patient level data on cardiovascular events. For one study, ${ }^{2122}$ self reports of unadjudicated events were supplied. Another study ${ }^{28}$ supplied self reports of hospital admissions and cause of death from death certificates. Each event was then independently adjudicated by two physicians blinded to the treatment allocation of the participants $(\mathrm{MB}$, $\mathrm{AG}$ ), and any disagreements were resolved by consensus. For another study, ${ }^{25}$ verified events from hospital discharge data were supplied along with causes of deaths from death certificates. The causes of death were again independently adjudicated. For two studies, ${ }^{1533}$ data from self reports, hospital admissions, and death certificates were independently adjudicated by a cardiologist or neurologist, as previously described. ${ }^{16}$ For six studies contributing trial level data, all data on cardiovascular events were supplied by the lead authors and were obtained from physician reported cause of death in one study ${ }^{27}$ and a combination of self reports and hospital discharge data in five studies. $^{192429-32}$

\section{End points}

The prespecified primary end points were time to first myocardial infarction, time to first stroke, and time to first event for the composite end point of myocardial infarction, stroke, or sudden death. The secondary end point was time to death (all cause mortality).

\section{Statistical analysis}

In trials with patient level data, we analysed each end point using a Cox proportional hazards model, with a dummy coded variable representing each study in the model, and we reported the hazard ratio, with 95\% confidence interval, and number needed to treat. The assumption of proportional hazards was explored by 
Table 1|Characteristics of 15 studies eligible for inclusion in meta-analysis

\begin{tabular}{|c|c|c|c|c|c|c|}
\hline Studies & $\begin{array}{l}\text { No in calcium group/ } \\
\text { No in control group }\end{array}$ & $\begin{array}{l}\text { Daily dose } \\
\text { and supplement type }\end{array}$ & $\begin{array}{l}\text { Trial duration } \\
\quad \text { (years) }\end{array}$ & Primary end point & $\begin{array}{l}\text { Baseline mean } \\
\text { age (years) }\end{array}$ & $\%$ female \\
\hline \multicolumn{7}{|c|}{ Patient level data on cardiovascular outcomes: } \\
\hline Reid $1993^{2122}$ & $68 / 67$ & $1 \mathrm{~g}$ lactogluconate-carbonate & 4 & Bone mineral density & 58 & 100 \\
\hline Baron $1999^{25}$ & $464 / 466$ & $1.2 \mathrm{~g}$ carbonate & 4 & Colorectal adenoma & 61 & 28 \\
\hline Grant $2005^{28}$ & $2617 / 2675$ & $1 \mathrm{~g}$ carbonate & $4^{*}$ & Low trauma fracture & 77 & 85 \\
\hline Reid $2006^{1516}$ & $732 / 739$ & $1 \mathrm{~g}$ citrate & 5 & Clinical fracture & 74 & 100 \\
\hline Reid $2008^{33}$ & $216 / 107$ & $0.6 \mathrm{~g}$ or $1.2 \mathrm{~g}$ citrate & 2 & Spine bone mineral density & 56 & 0 \\
\hline Subtotal/average $†$ & $4097 / 4054$ & - & 4.1 & - & 73 & 78 \\
\hline \multicolumn{7}{|c|}{ Trial level data on cardiovascular outcomesł: } \\
\hline Dawson-Hughes $1990^{19}$ & $238 / 123$ & $0.5 \mathrm{~g}$ carbonate or citrate & 2 & Spine bone mineral density & 58 & 100 \\
\hline Riggs $1998^{24}$ & $119 / 117$ & $1.6 \mathrm{~g}$ citrate & 4 & Bone mineral density & 66 & 100 \\
\hline Bonithon-Kopp $2000^{27}$ & $204 / 212$ & $2 \mathrm{~g}$ lactogluconate-carbonate & 3 & Colorectal adenoma & 59 & 37 \\
\hline Prince $2006^{29}$ & $730 / 730$ & $1.2 \mathrm{~g}$ carbonate & 5 & Osteoporotic fracture & 75 & 100 \\
\hline Bonnick $2007^{30}$ & $282 / 281$ & $1 \mathrm{~g}$ carbonate & 2 & Spine bone mineral density & 66 & 100 \\
\hline Lappe $2007^{3132}$ & $446 / 288$ & $1.4 \mathrm{~g}$ citrate or $1.5 \mathrm{~g}$ carbonate & 4 & Fracture incidence & 67 & 100 \\
\hline Subtotal/average $†$ & $2019 / 1751$ & - & 3.8 & - & 68 & 93 \\
\hline Total/average $†$ & $6116 / 5805$ & & 4.0 & & 72 & 83 \\
\hline \multicolumn{7}{|c|}{ No data on cardiovascular outcomes: } \\
\hline Smith $1989^{18} \S$ & $84 / 85$ & $1.5 \mathrm{~g}$ carbonate & 4 & Arm bone mineral density & 51 & 100 \\
\hline Elders $1991^{20}$ & $198 / 97$ & $\begin{array}{l}1 \mathrm{~g} \text { or } 2 \mathrm{~g} \text { lactogluconate-carbonate } \\
\text { or citrate }\end{array}$ & 2 & Spine bone mineral density & NA & 100 \\
\hline Recker $1996^{23}$ & $95 / 102$ & $1.2 \mathrm{~g}$ carbonate & 4 & Vertebral fracture & 74 & 100 \\
\hline Peacock $2000^{26}$ & $126 / 135$ & $0.75 \mathrm{~g}$ citrate & 4 & Hip bone mineral density & 76 & 72 \\
\hline Subtotal/average $†$ & $503 / 419$ & - & 4.0 & - & 69 & 88 \\
\hline \multicolumn{7}{|c|}{$\begin{array}{l}\text { NA=not available. } \\
\text { *All participants were followed for two years with a median follow-up of } 45 \text { months. } \\
\text { †Weighted by person years of follow-up. } \\
\text { †Complete trial level data were available for two studies. }{ }^{29}{ }^{31} \text { Partially complete data were available for four studies }{ }^{19} 242730 \text { (see table } 2 \text { for details). } \\
\text { §No original records remained but lead author recalled no heart attacks in either treatment group. }\end{array}$} \\
\hline
\end{tabular}

carrying out a test for proportionality of the interaction between variables included in the model and the logarithm of time. For a small number of events $(<10 \%)$ the timing was unknown. We treated these events as if they had occurred on the last day of follow-up for that participant. Possible confounding by covariates was assessed by repeating these models including prespecified covariates likely to be associated with cardiovascular outcomes (age, sex, smoking status, presence of diabetes, dyslipidaemia, and hypertension at baseline, and history of coronary heart disease) where data were available for more than $80 \%$ of participants. Prespecified subgroup analyses for dietary calcium, age, sex, vitamin D status (serum 25-hydroxyvitamin D $\geq 50 \mathrm{nmol} / 1$ or $<50 \mathrm{nmol} / \mathrm{l}$ ), and supplement type were done using interaction terms between treatment allocation and the factor of interest.

We used Poisson regression models to assess the relation between the total number of events and treatment allocation. Because recurrent cardiovascular events in an individual are unlikely to be independent, we used Poisson regression with general estimating equations to account for the intra-individual dependence of events.

To assess statistical heterogeneity between summary data at trial level we used Cochran's Q statistic $(\mathrm{P}<0.10)$ and the $\mathrm{I}^{2}$ statistic $\left(\mathrm{I}^{2}>50 \%\right)$. No significant statistical heterogeneity existed between trials in any of the analyses. We used random effects models to pool summary data at trial level. Publication bias was assessed using Funnel plots and Egger's regression model. ${ }^{34}$ Analyses were done using SAS version 9.1 or Comprehensive Meta-analysis version 2 (Biostat, Englewood, NJ). All tests were two tailed and we considered $\mathrm{P}<0.05$ as significant.

\section{RESULTS}

Figure 1 shows the results of the literature search and table 1 the characteristics of the eligible studies. The quality of the five studies contributing patient level data has been independently assessed in previous systematic reviews. $^{33536}$

All 11 eligible trials were double blind, randomised studies. The method of randomisation was stated explicitly in seven: one used a central randomisation service and six used computer generated random numbers. Allocation concealment was explicitly described in four studies. Ten studies gave details of participants who withdrew or were lost to follow-up. Compliance was reported in all 11 studies, but the definitions for compliance differed between studies and were not always comparable. In general, studies reported compliance of more than $75 \%$ in participants who were taking tablets at study completion. Table 2 shows the baseline cardiovascular characteristics, dietary calcium intake, and vitamin D status of participants. 
Table 2|Baseline cardiovascular and other variables in trials with patient or trial level data available for cardiovascular outcomes. Values are means (standard deviations) unless stated otherwise

\begin{tabular}{|c|c|c|c|c|c|c|c|c|}
\hline Studies & $\begin{array}{l}\text { Dietary calcium } \\
\text { (mg/day) }\end{array}$ & $\begin{array}{c}\text { Vitamin D* } \\
(\mathrm{nmol} / \mathrm{l})\end{array}$ & $\begin{array}{l}\text { Weight } \\
\text { (kg) }\end{array}$ & $\begin{array}{c}\text { Current smoker } \\
(\%)\end{array}$ & $\begin{array}{l}\text { Hypertension } \\
\text { (\%) }\end{array}$ & $\begin{array}{l}\text { Diabetes } \\
\text { (\%) }\end{array}$ & $\begin{array}{l}\text { Ischaemic heart } \\
\text { disease (\%) }\end{array}$ & $\begin{array}{l}\text { Lipid disorder } \\
\text { (\%) }\end{array}$ \\
\hline Dawson-Hughes ${ }^{19}$ & $406(84)$ & NA & NA & NA & NA & NA & NA & NA \\
\hline Reid $^{2122}$ & $750(290)$ & $93(37)$ & $65(9)$ & 10 & 9 & 0 & 2 & 1 \\
\hline $\operatorname{Riggs}^{24}$ & $710(290)$ & $80(25)$ & NA & NA & NA & NA & NA & NA \\
\hline Baron $^{25}$ & $880(440)$ & $73(27)$ & $82(15)$ & 19 & 37 & 10 & 12 & 32 \\
\hline Bonithon-Kopp ${ }^{27}$ & $980(380)$ & NA & NA & NA & NA & NA & NA & NA \\
\hline Grant $^{28}$ & $820(350)$ & $45(18) \dagger$ & 65 (13) & 12 & NA & 8 & NA & NA \\
\hline Reid $^{1516}$ & $860(390)$ & $54(18)$ & $67(11)$ & 3 & 29 & 3 & 8 & 8 \\
\hline Prince $^{29}$ & 915 & NA & 69 (13) & NA & NA & NA & NA & NA \\
\hline Bonnick $^{30}$ & $1240(580)$ & NA & NA & 0.4 & NA & NA & NA & NA \\
\hline Lappe $^{3132}$ & 1070 & $72(20)$ & 77 (15) & NA & NA & NA & NA & NA \\
\hline Reid $^{33}$ & $870(450)$ & $92(33)$ & $83(12)$ & 3 & 8 & 0.3 & 0.3 & 4 \\
\hline
\end{tabular}

NA=not available

*25-hydroxyvitamin D.

†25-hydroxyvitamin D measured in sample of 80 participants.

Cardiovascular events by treatment allocation are shown in table 3 .

Patient level analysis

Table 4 shows the baseline characteristics of the treatment groups in the five studies contributing patient level data. The median (interquartile range) duration of follow-up in both groups was 3.6 (2.7-4.3) years.

In total, 143 people allocated to calcium had a myocardial infarction during follow-up compared with 111 allocated to placebo. The risk of incident myocardial infarction in those allocated to calcium increased by $31 \%$ (hazard ratio $1.31,95 \%$ confidence interval 1.02 to $1.67, \mathrm{P}=0.035$. fig 2). During follow-up, 167 people allocated to calcium and 143 allocated to placebo had a stroke $(1.20,0.96$ to $1.50, \mathrm{P}=0.11), 293$ people allocated to calcium and 254 allocated to placebo had any of myocardial infarction, stroke, or sudden death $(1.18,1.00$ to $1.39, \mathrm{P}=0.057)$, and 519 people allocated to calcium and 487 allocated to placebo died (1.09, 0.96 to $1.23, \mathrm{P}=0.18)$. The number needed to treat (NNT) with calcium for five years to cause one incident event was 69 for myocardial infarction, 100 for stroke, 61 for any of myocardial infarction, stroke, or sudden death, and 77 for death. Adjusting for prespecified covariates related to cardiovascular outcomes with data available for more than $80 \%$ of participants (age, sex, smoking status, and diabetes) did not change the results of the primary analyses.

Prespecified subgroup analyses showed a significant interaction between treatment allocation and dietary calcium intake for myocardial infarction. Calcium treatment was associated with an increased risk of myocardial infarction in people with dietary calcium intake above the median of $805 \mathrm{mg}$ /day (hazard ratio 1.85 , $95 \%$ confidence interval 1.28 to 2.67 ) but no increased risk in those with dietary calcium intake below the median $(0.98,0.69$ to $1.38, \mathrm{P}$ for interaction 0.01$)$. When the cohort was divided by fifths of dietary calcium intake rounded to the nearest $100 \mathrm{mg} /$ day, the respective hazard ratios (95\% confidence intervals) for the effect of calcium treatment on myocardial infarction were 1.18 ( 0.70 to 2.00$)$ for $<500 \mathrm{mg} /$ day, 0.68 (0.39 to 1.18 ) for $500-699 \mathrm{mg}$ /day, 2.28 (1.26 to 4.15) for 700-899 mg/day, 1.81 (0.97 to 3.41) for 900$1099 \mathrm{mg} /$ day, and 1.41 (0.81 to 2.48 ) for $\geq 1100 \mathrm{mg} /$ day; test for linear trend when hazard ratios are expressed relative to the $<500 \mathrm{mg} / \mathrm{d}$ fifth, $\mathrm{P}=0.12$. Interactions between treatment allocation and age, sex, vitamin D status, or supplement type for myocardial infarction were not significant, nor were they between treatment allocation and any of these variables or dietary calcium intake for stroke, the composite end point, or death.

Recurrent cardiovascular events tended to be more common in people allocated to calcium. Comparing people allocated to calcium with those allocated to placebo, 19 versus 13 had more than one myocardial infarction $(\mathrm{P}=0.38), 21$ versus 13 had more than one stroke $(\mathrm{P}=0.23)$, and 59 versus 32 had more than one of myocardial infarction, stroke, or sudden death $(\mathrm{P}=0.006)$. Poisson regression models with general estimating equations were used to estimate the effect of calcium on the total number of events, including incident and recurrent events. Overall, 164 myocardial infarctions occurred in people allocated to calcium compared with 125 in those allocated to placebo (relative risk $1.32,95 \%$ confidence interval 1.02 to 1.71 , $\mathrm{P}=0.032)$. Stroke occurred in 190 people allocated to calcium compared with 156 allocated to placebo (1.24, 0.99 to $1.56, \mathrm{P}=0.07)$. In total, 361 myocardial infarctions, strokes, or sudden deaths occurred in people allocated to calcium compared with 287 in people allocated to calcium $(1.27,1.07$ to $1.51, \mathrm{P}=0.006)$.

Trial level analysis

Table 3 shows summary data on cardiovascular events at trial level. Eight studies ${ }^{151621222528-33}$ were included in the main analysis. A further three trials ${ }^{192427}$ had data only available for subgroups of participants. These three trials were included in a sensitivity analysis that included data from all 11 trials. Publication bias 
Table 3| Number of people with cardiovascular events and deaths by treatment allocation

\begin{tabular}{|c|c|c|c|c|c|c|c|c|c|c|}
\hline \multirow[b]{2}{*}{ Studies } & \multicolumn{5}{|c|}{ Calcium group } & \multicolumn{5}{|c|}{ Placebo group } \\
\hline & $\begin{array}{c}\text { No of } \\
\text { participants }\end{array}$ & $\begin{array}{l}\text { Myocardial } \\
\text { infarction }\end{array}$ & Stroke & Composite* & Death & $\begin{array}{c}\text { No of } \\
\text { participants }\end{array}$ & $\begin{array}{l}\text { Myocardial } \\
\text { infarction }\end{array}$ & Stroke & Composite* & Death \\
\hline Dawson-Hughes ${ }^{19} \dagger$ & 238 & 0 & 0 & NA & NA & 123 & 0 & 1 & NA & NA \\
\hline Reid $^{2122}$ & 68 & 0 & 2 & 2 & 0 & 67 & 0 & 1 & 1 & 0 \\
\hline $\operatorname{Riggs}^{24} \ddagger$ & 119 & 0 & 0 & 0 & 1 & 117 & 0 & 0 & 0 & 0 \\
\hline Baron $^{25}$ & 464 & 20 & 15 & 31 & 25 & 466 & 17 & 11 & 28 & 22 \\
\hline Bonithon-Kopp ${ }^{27} \S$ & 204 & 0 & 1 & 1 & 8 & 212 & 0 & 0 & 1 & 9 \\
\hline Grant $^{28} \mathbb{q}$ & 1311 & 45 & 56 & 97 & 238 & 1332 & 39 & 48 & 86 & 217 \\
\hline Grant $^{28 \star \star}$ & 1306 & 44 & 60 & 100 & 220 & 1343 & 34 & 58 & 89 & 218 \\
\hline Reid $^{1516}$ & 732 & 31 & 34 & 60 & 34 & 739 & 21 & 25 & 50 & 29 \\
\hline Prince ${ }^{29}+\dagger$ & 730 & 21 & 38 & 56 & 29 & 730 & 17 & 40 & 56 & 38 \\
\hline 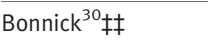 & 282 & 0 & 1 & NA & 2 & 281 & 0 & 2 & NA & 1 \\
\hline Lappe $3132+†$ & 446 & 2 & 5 & 8 & NA & 288 & 2 & 4 & 8 & NA \\
\hline $\operatorname{Reid}^{33}$ & 216 & 3 & 0 & 3 & 2 & 107 & 0 & 0 & 0 & 1 \\
\hline Total & 6116 & 166 & 212 & 358 & 559 & 5805 & 130 & 190 & 319 & 535 \\
\hline
\end{tabular}

NA=not available.

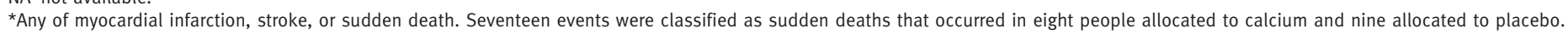
tUnpublished trial level data provided by author. Data on stroke available only for participants who withdrew from study.

fUnpublished trial level data provided by author. Data available only for participants who withdrew from study.

$\S$ Unpublished trial level data provided by author. Data on cause of death only.

ๆCalcium versus placebo arms in Randomised Evaluation of Calcium or Vitamin D (RECORD) study.

${ }^{* *}$ Calcium and vitamin D versus placebo plus vitamin D arms in Randomised Evaluation of Calcium or Vitamin D (RECORD) study.

††Unpublished trial level data provided by author.

‡łUnpublished trial level data provided by Boyd Scott.

was not evident on inspection of Funnel plots or in Egger's regression model in any analysis $(\mathrm{P}>0.40$ for all analyses). Figure 3 shows the results of the main analysis. Allocation to calcium supplements was associated with an increased risk of myocardial infarction (relative risk 1.27, 95\% confidence interval 1.01 to $1.59, \mathrm{P}=0.038$ ) but not stroke, the composite end point, or death. Including data from the three additional studies in the sensitivity analysis did not significantly change the results for any end point.

\section{DISCUSSION}

In this pooled analysis of around 12000 participants from 11 randomised controlled trials, calcium supplements were associated with about a $30 \%$ increase in the incidence of myocardial infarction and smaller, nonsignificant, increases in the risk of stroke and mortality. When recurrent events in 10-17\% of participants were included in analyses, the results were similar, although the relative risks tended to be slightly larger. The findings were consistent across trials, with an increased relative risk of myocardial infarction with calcium observed in six of the seven trials in which at least one event occurred, although no individual trial reported a statistically significant effect. The risk of myocardial infarction with calcium tended to be greater in those with dietary calcium intake above the median but was independent of age, sex, and type of supplement.

\section{Limitations of the review}

Our study has some limitations. We excluded studies that compared coadministered calcium and vitamin D supplements with placebo. The results therefore may not apply to coadministered calcium and vitamin D supplements. None of the trials had cardiovascular outcomes as the primary end points, and data on cardiovascular events were not gathered in a standardised manner. In only two of the trials were the data adjudicated by blinded trial investigators. However, unless there was differential misclassification or misreporting of cardiovascular events in people treated with calcium, this is unlikely to alter the results, because the data came from blinded, placebo controlled trials. Incomplete or no data on cardiovascular outcomes were available for seven trials in our analysis, comprising about $15 \%$ of the total number of participants. However, the small size of these trials and the consistency of the findings in the other eight larger trials suggest the missing data are unlikely to have substantially changed the results.

\section{Comparison with other studies}

The current findings are consistent with trials of patients with renal failure, in which calcium supplements were associated with an increase in mortality. ${ }^{13}$ Few comparable data are available from observational studies of calcium supplements. One study reported a $24 \%$ increase in coronary heart disease in Finnish postmenopausal women using calcium supplements (with or without vitamin D) compared with non-users. ${ }^{37}$ Non-fatal myocardial infarction in US men using calcium supplements compared with non-users did not increase significantly, although the relative risk for each fifth of supplement intake ranged between 1.02 and 1.07. ${ }^{38}$

The relations between dietary calcium intake and cardiovascular events have also been examined. The inverse relation between calcium intake and 

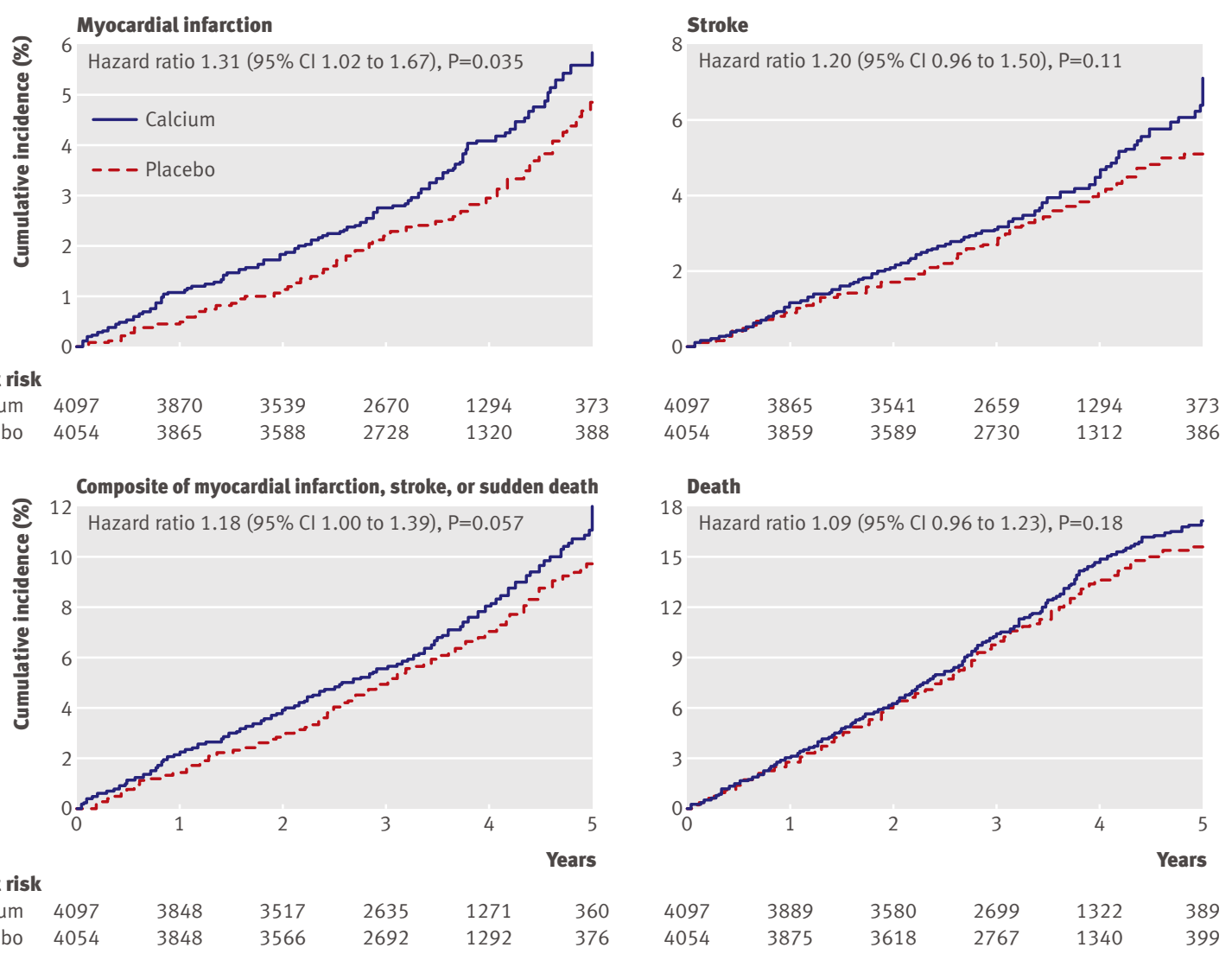

Fig 2 | Cumulative incidence of myocardial infarction, stroke, composite of myocardial infarction, stroke, or sudden death, and death by treatment allocation in five studies that contributed patient level data

standardised mortality ratios for ischaemic heart disease in the United Kingdom was strong. ${ }^{6}$ In two US prospective observational studies, women in the highest fourth of calcium intake had 30-40\% lower cardiovascular mortality than those in the lowest fourth, ${ }^{7}$ and those in the highest fifth of calcium intake had a 30-40\% lower risk of ischaemic stroke than those in the lowest fifth. ${ }^{8}$ No relation between calcium intake and ischaemic heart disease or stroke was observed in prospective

Table 4 | Baseline characteristics of participants in five studies included in patient level analysis by treatment allocation. Values are percentages unless stated otherwise

\begin{tabular}{|c|c|c|}
\hline Characteristics & Calcium group & Placebo group \\
\hline Median (interquartile range) age (years) & $74.5(70-79)$ & $74.6(71-79)$ \\
\hline Women & 76.5 & 79.2 \\
\hline White ethnicity & 97.2 & 97.7 \\
\hline Mean (SD) weight (kg) & $68.4(14.1)$ & $67.9(13.7)$ \\
\hline Mean (SD) dietary calcium (mg/day) & $837(377)$ & $831(370)$ \\
\hline Mean (SD) 25-hydroxyvitamin D (nmol/l)* & $66.1(28.9)$ & $64.3(27.5)$ \\
\hline Current smoker & 11.0 & 10.2 \\
\hline Hypertension† & 28.0 & 28.4 \\
\hline Ischaemic heart disease $†$ & 8.1 & 7.8 \\
\hline Lipid disorder† & 14.8 & 15.4 \\
\hline Diabetes & 7.0 & 6.7 \\
\hline \multicolumn{3}{|c|}{$\begin{array}{l}\text { Proportion of women was significantly higher in placebo group because one study that only involved men had a } \\
\text { 2:1 ratio of allocation to calcium or placebo. }{ }^{33} \text { No other differences existed between groups. Medical conditions } \\
\text { at baseline were self reported by participants. } \\
\text { *Data available from four studies for } 1445 \text { participants in calcium groups and } 1355 \text { in placebo groups. } \\
\text { †Data available from four studies for } 1480 \text { participants in calcium groups and } 1379 \text { in placebo groups. }\end{array}$} \\
\hline
\end{tabular}

studies of US men, ${ }^{3839}$ or of Dutch civil servants. ${ }^{40}$ Thus, in contrast with the observational and interventional studies of calcium supplements, these observational studies do not show increased cardiovascular risks with higher dietary calcium intake. These differences suggest that cardiovascular risks from high calcium intake might be restricted to use of calcium supplements.

A body of evidence related to the current work comes from studies comparing coadministered calcium and vitamin D supplements with placebo, which were excluded from our meta-analysis. Recently, the Women's Health Initiative reported that calcium and vitamin D had no effect on the risk of coronary heart disease or stroke..$^{41}$ The findings of that study might differ from ours for several reasons. The Women's Health Initiative used low dose vitamin D supplements, and vitamin D deficiency has been associated with increased risk of cardiovascular disease $^{42}$ and vitamin D supplementation with decreased mortality. ${ }^{17}$ Also, the participants differed from those in our meta-analysis: on average they were younger (mean age $62 v 75$ years), heavier (mean weight 76 v $68 \mathrm{~kg} ; 34 \%$ in Women's Health Initiative $v 10 \%$ of women in our meta-analysis weighed $>80 \mathrm{~kg}$ ), had higher calcium intakes (mean 1150 ข $830 \mathrm{mg} /$ day), and a higher proportion were using hormone replacement therapy $(52 \% \quad v<3 \%$ in our meta-analysis). Overall, $54 \%$ were taking non- 

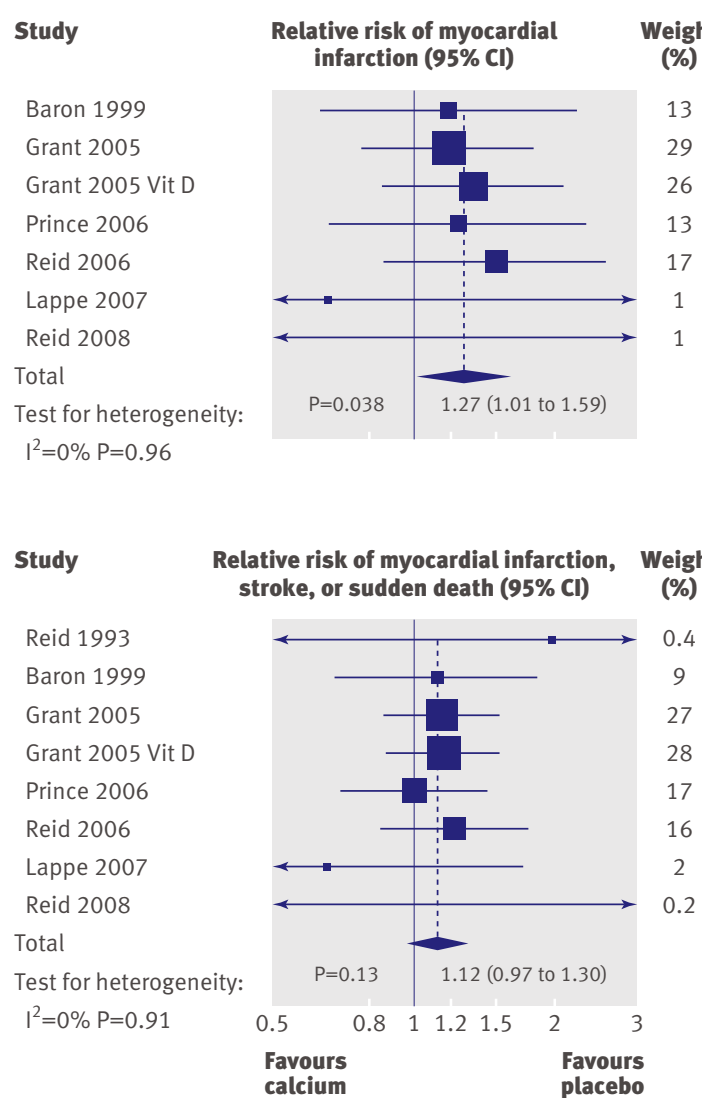

Study

13

29

26

1

1

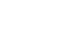

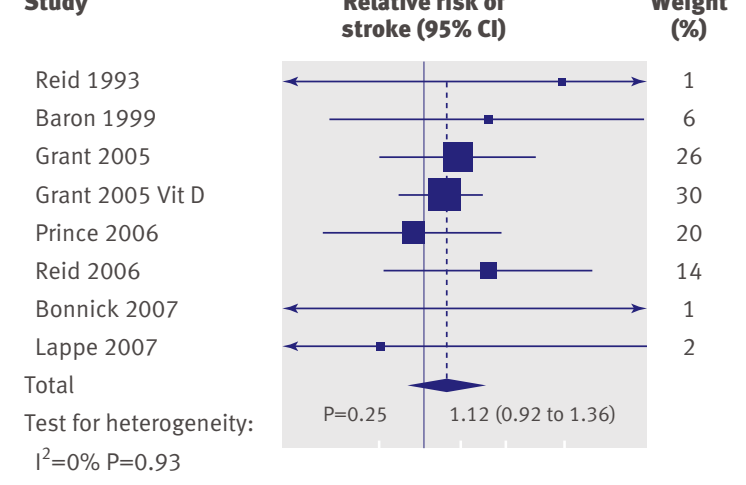

$\mathrm{I}^{2}=0 \% \mathrm{P}=0.93$

Fig 3 | Random effects models of effect of calcium supplementation on cardiovascular events and death. Full data were available from these eight trials, but some trials do not appear in the figures because no events occurred during the trial: no myocardial infarctions occurred in the study by Reid $1993^{2122}$ or Bonnick $2007,{ }^{30}$ no strokes occurred in the study by Reid $2008,{ }^{33}$ and no deaths occurred in the study by Reid $1993 .{ }^{2122}$ Data on composite end point were not available for the study by Bonnick $2007^{30}$ or Lappe $2007 . .^{3132}$ Grant 2005 is a Randomised Evaluation of Calcium or Vitamin D (RECORD) study calcium versus placebo arms, and Grant 2005 vitamin D is a RECORD study calcium plus vitamin D versus vitamin D plus placebo arms

protocol calcium supplements at baseline $(30 \%$ were taking $\geq 500 \mathrm{mg} /$ day), increasing to $69 \%$ at the final visit, ${ }^{4344}$ compared with $1.2 \%$ taking non-protocol calcium supplements at baseline in our meta-analysis. In the subgroups of women in the Women's Health Initiative who most closely approximated the participants in our analyses (age 70-79 years, body mass index $<30 \mathrm{~kg} / \mathrm{m}^{2}$, total calcium intake $<800 \mathrm{mg} /$ day), the confidence intervals of the hazard ratios for coronary heart disease with calcium and vitamin D included the hazard ratio for myocardial infarction we observed. It would be valuable to reanalyse the results of the Women's Health Initiative to assess the effects of calcium and vitamin $\mathrm{D}$ in non-obese women and in women not taking non-protocol calcium supplements. Interestingly, the only study in our analysis that reported a relative risk of less than 1.0 for myocardial infarction with calcium also had high non-protocol use of calcium supplements. ${ }^{31} 3245$

The current analyses do not deal with the mechanisms by which calcium supplements might increase the risk of myocardial infarction, but we have reviewed this elsewhere. ${ }^{46}$ Calcium supplements acutely increase serum calcium levels to a modest degree. ${ }^{47}$ Serum calcium levels have been positively associated with an increased incidence of myocardial infarction in large observational studies. ${ }^{48-50}$ Primary hyperparathyroidism, a condition in which serum calcium levels are raised, has also been associated with an increased risk of cardiovascular events and death. ${ }^{5152}$ Ingestion of equivalent doses of calcium from dairy products has a much smaller effect than calcium supplements on serum calcium levels, ${ }^{53}$ which might account for the absence of a detrimental vascular effect of dietary calcium intake in the observational studies reviewed. Vascular calcification is an established risk factor for cardiovascular disease, ${ }^{54}$ and the process of vascular calcification is similar to osteogenesis. ${ }^{55}$ Because calcium supplements increase bone density it is possible that they may also increase vascular calcification and thereby cardiovascular events. In patients with renal failure (both dialysis and predialysis populations) calcium supplements accelerate vascular calcification and increase mortality. ${ }^{12-14}$ Our graphical data are consistent with the possibility that an increased risk of myocardial infarction with calcium supplements emerges quickly, pointing to mechanisms such as increased coagulability or altered vascular flow, perhaps mediated directly through the calcium sensing receptor or indirectly through alterations in calcitropic hormones. 


\section{WHAT IS ALREADY KNOWN ON THIS TOPIC}

Calcium supplements are commonly taken by older people for skeletal health

A randomised placebo controlled trial suggested calcium supplements might increase the risk of myocardial infarction and cardiovascular events

\section{WHAT THIS STUDY ADDS}

A meta-analysis of trials totalling 12000 participants found that calcium supplements increase the risk of myocardial infarction by about $30 \%$

Given the modest benefits of calcium supplements on bone density and fracture prevention, a reassessment of the role of calcium supplements in the management of osteoporosis is warranted
AA is funded by a career scientist award of the chief scientist office of the Scottish government health directorates. The Health Services Research Unit is funded by the chief scientist office of the Scottish government health directorates. The sponsors of the study had no role in design and conduct of the study; collection, management, analysis, and interpretation of the data; and preparation, review, or approval of the manuscript. The authors are independent from the funders. Competing interests: All authors have completed the unified competing interest form at www.icmje.org/coi_disclosure.pdf (available on request from the corresponding author) and declare that: (1) no author has support from companies for the submitted work; (2) IR has received research support from and acted as a consultant for Fonterra that might have an interest in the submitted work in the previous 3 years; JB, IR, AA and GM had study drugs for clinical trials of calcium supplementation supplied by Wyeth; Mission Pharmacal; Shire Pharmaceuticals and Nycomed; and Shire Pharmaceuticals and Nycomed, respectively, might have an interest in the submitted work in the previous 3 years; (3) their spouses, partners, or children have no financial relationships that may be relevant to the submitted work; and (4) no author has non-financial interests that may be relevant to the submitted work.

Ethical approval: Not required.

Data sharing: No additional data available. patient level data ${ }_{152122252833}$ the hazard ratio for fracture was 0.90 (95\% confidence interval 0.80 to 1.01$)$ and NNT for five years to prevent one fracture was 39. A recent meta-analysis of the effect of calcium with or without vitamin $\mathrm{D}$ on fracture reported a similar NNT for five years of $48 .^{3}$ Later meta-analyses reported that combined supplementation with calcium and vitamin D reduced fractures, whereas vitamin $\mathrm{D}$ alone did not. ${ }^{5657}$ Incorporating the results from the current analysis of studies contributing patient level data, treatment of 1000 people with calcium for five years would cause an additional 14 myocardial infarctions, 10 strokes, and 13 deaths, and prevent 26 fractures.

\section{Conclusions}

In summary, randomised studies suggest that calcium supplements without coadministered vitamin D are associated with an increased incidence of myocardial infarction. The vascular effects of calcium supplements, especially without vitamin $\mathrm{D}$, should be studied further. Although the magnitude of the increase in risk is modest, the widespread use of calcium supplements means that even a small increase in incidence of cardiovascular disease could translate into a large burden of disease in the population. The likely adverse effect of calcium supplements on cardiovascular events, taken together with the possible adverse effect on incidence of hip fracture ${ }^{258}$ and its modest overall efficacy in reducing fracture (about 10\% reduction in total fractures $)^{23}$ suggest that a reassessment of the role of calcium supplements in the prevention and treatment of osteoporosis is warranted.

We thank the investigators who provided unpublished data on cardiovascular events from their studies including Larry Riggs, Richard Prince, Claire Bonithon-Kopp, Joan Lappe, Boyd Scott, and Kathy Zhu, as well as Adrian M Grant, M K Campbell, Alison M McDonald and Gladys C McPherson from the Randomised Evaluation of Calcium or Vitamin D trial. Contributors: MJB, AG, and IRR drafted the protocol. AA and JAB critically revised the protocol. MJB and $A G$ carried out the literature search and event adjudication. All authors provided individual patient data from their studies. MJB and GDG did the analyses. MJB drafted the paper. All authors critically reviewed the paper. MJB had full access to all the data in the study and takes responsibility for the integrity of the data and the accuracy of the data analysis. MJB is the guarantor

Funding: This review was funded by the Health Research Council of New Zealand and the University of Auckland School of Medicine Foundation.
1 Sambrook P, Cooper C. Osteoporosis. Lancet 2006;367:2010-8.

2 Bischoff-Ferrari HA, Dawson-Hughes B, Baron JA, Burckhardt P, Li R, Spiegelman D, et al. Calcium intake and hip fracture risk in men and women: a meta-analysis of prospective cohort studies and randomized controlled trials. Am / Clin Nutr 2007;86:1780-90.

3 Tang BMP, Eslick GD, Nowson C, Smith C, Bensoussan A. Use of calcium or calcium in combination with vitamin D supplementation to prevent fractures and bone loss in people aged 50 years and older: a meta-analysis. Lancet 2007;370:657-66.

4 American Association of Clinical Endocrinologists. Medical guidelines for clinical practice for the prevention and treatment of postmenopausal osteoporosis. Endo Pract 2003;9:545-64.

5 National Osteoporosis Foundation. Physician's guide to prevention and treatment of osteoporosis. National Osteoporosis Foundation, 2008

6 Knox EG. Ischaemic-heart-disease mortality and dietary intake of calcium. Lancet 1973;1:1465-7.

7 Bostick RM, Kushi LH, Wu Y, Meyer KA, Sellers TA, Folsom AR. Relation of calcium, vitamin $\mathrm{D}$, and dairy food intake to ischemic heart disease mortality among postmenopausal women. Am J Epidemiol 1999;149:151-61

8 Iso H, Stampfer MJ, Manson JE, Rexrode K, Hennekens $\mathrm{CH}$ Colditz GA, et al. Prospective study of calcium, potassium, and magnesium intake and risk of stroke in women. Stroke 1999;30:1772-9.

9 Griffith LE, Guyatt GH, Cook RJ, Bucher HC, Cook DJ. The influence of dietary and nondietary calcium supplementation on blood pressure -an updated metaanalysis of randomized controlled trials. Am J Hypertens 1999;12:84-92.

10 Reid IR, Mason B, Horne A, Ames R, Clearwater J, Bava U, et al. Effects of calcium supplementation on serum lipid concentrations in normal older women: a randomized controlled trial. Am J Med 2002;112:343-7.

11 Reid IR, Horne A, Mason B, Ames R, Bava U, Gamble GD. Effects of calcium supplementation on body weight and blood pressure in normal older women: a randomized controlled trial. J Clin Endocrino Metab 2005;90:3824-9.

12 Goodman WG, Goldin J, Kuizon BD, Yoon C, Gales B, Sider D, et al. Coronary-artery calcification in young adults with end-stage renal disease who are undergoing dialysis. N Engl J Med 2000;342:1478-83.

13 Block GA, Raggi P, Bellasi A, Kooienga L, Spiegel DM. Mortality effect of coronary calcification and phosphate binder choice in incident hemodialysis patients. Kidney Int 2007;71:438-41.

14 Russo D, Miranda I, Ruocco C, Battaglia Y, Buonanno E, Manzi S, et al. The progression of coronary artery calcification in predialysis patients on calcium carbonate or sevelamer. Kidney Int 2007;72:1255-61.

15 Reid IR, Mason B, Horne A, Ames R, Reid HE, Bava U, et al. Randomized controlled trial of calcium in healthy older women. $\mathrm{Am}$ J Med 2006;119:777-85

16 Bolland MJ, Barber PA, Doughty RN, Mason B, Horne A, Ames R, et al. Vascular events in healthy older women receiving calcium supplementation: randomised controlled trial. BM/ 2008;336:262-6.

17 Autier P, Gandini S. Vitamin D supplementation and total mortality: a meta-analysis of randomized controlled trials. Arch Intern Med 2007;167:1730-7. 
18 Smith EL, Gilligan C, Smith PE, Sempos CT. Calcium supplementation and bone loss in middle-aged women. Am J Clin Nutr 1989;50:833-42.

19 Dawson-Hughes B, Dallal GE, Krall EA, Sadowski L, Sahyoun N, Tannenbaum S. A controlled trial of the effect of calcium supplementation on bone density in postmenopausal women. $N$ Engl J Med 1990;323:878-83.

20 Elders PJ, Netelenbos JC, Lips P, van Ginkel FC, Khoe E, Leeuwenkamp OR, et al. Calcium supplementation reduces vertebral bone loss in perimenopausal women: a controlled trial in 248 women between 46 and 55 years of age. J Clin Endocrinol Metab 1991;73:533-40.

21 Reid IR, Ames RW, Evans MC, Gamble GD, Sharpe SJ. Effect of calcium supplementation on bone loss in postmenopausal women. $N$ Engl Med 1993;328:460-4.

22 Reid IR, Ames RW, Evans MC, Gamble GD, Sharpe SJ. Long-term effects of calcium supplementation on bone loss and fractures in postmenopausal women: a randomized controlled trial. Am J Med 1995;98:331-5.

23 Recker RR, Hinders S, Davies KM, Heaney RP, Stegman MR, Lappe JM, et al. Correcting calcium nutritional deficiency prevents spine fractures in elderly women. J Bone Miner Res 1996;11:1961-6.

24 Riggs BL, O'Fallon WM, Muhs J, O’Connor MK, Kumar R, Melton LJ 3rd. Long-term effects of calcium supplementation on serum parathyroid hormone level, bone turnover, and bone loss in elderly women. J Bone Miner Res 1998;13:168-74.

25 Baron JA, Beach M, Mandel JS, van Stolk RU, Haile RW, Sandler RS, et al. Calcium supplements for the prevention of colorectal adenomas. Calcium Polyp Prevention Study Group. N Engl J Med 1999;340:101-7.

26 Peacock M, Liu G, Carey M, McClintock R, Ambrosius W, Hui S, et al. Effect of calcium or $250 \mathrm{H}$ vitamin D3 dietary supplementation on bone loss at the hip in men and women over the age of 60. J Clin Endocrinol Metab 2000;85:3011-9.

27 Bonithon-Kopp C, Kronborg O, Giacosa A, Rath U, Faivre J. Calcium and fibre supplementation in prevention of colorectal adenoma recurrence: a randomised intervention trial. European Cancer Prevention Organisation Study Group. Lancet 2000;356:1300-6.

28 Grant AM, Avenell A, Campbell MK, McDonald AM, MacLennan GS, McPherson GC, et al. Oral vitamin D3 and calcium for secondary prevention of low-trauma fractures in elderly people (Randomised Evaluation of Calcium Or vitamin D, RECORD): a randomised placebocontrolled trial. Lancet 2005;365:1621-8.

29 Prince RL, Devine A, Dhaliwal SS, Dick IM. Effects of calcium supplementation on clinical fracture and bone structure: results of a 5-year, double-blind, placebo-controlled trial in elderly women. Arch Intern Med 2006;166:869-75.

30 Bonnick S, Broy S, Kaiser F, Teutsch C, Rosenberg E, DeLucca P, et al. Treatment with alendronate plus calcium, alendronate alone, or calcium alone for postmenopausal low bone mineral density. Curr Med Res Opin 2007;23:1341-9.

31 Lappe JM, Travers-Gustafson D, Davies KM, Recker RR, Heaney RP. Vitamin D and calcium supplementation reduces cancer risk: results of a randomized trial. Am J Clin Nutr 2007;85:1586-91.

32 Lappe JM, Heaney RP. Calcium supplementation: results may not be generalisable. $B M / 2008 ; 336: 403$

33 Reid IR, Ames R, Mason B, Reid HE, Bacon CJ, Bolland MJ, et al. Randomized controlled trial of calcium supplementation in healthy, nonosteoporotic, older men. Arch Intern Med 2008;168:2276-82.

34 Egger M, Davey Smith G, Schneider M, Minder C. Bias in metaanalysis detected by a simple, graphical test. BMJ 1997;315:629-34

35 Chung M, Balk EM, Brendel M, Ip S, Lau J, Lee J, et al. Vitamin D and calcium: a systematic review of health outcomes. Evidence report No 183. Agency for Healthcare Research and Quality, 2009.

36 Weingarten MA, Zalmanovici A, Yaphe J. Dietary calcium supplementation for preventing colorectal cancer and adenomatous polyps. Cochrane Database Syst Rev 2008;1:CD003548.

37 Pentti K, Tuppurainen MT, Honkanen R, Sandini L, Kroger H, Alhava E, et al. Use of calcium supplements and the risk of coronary heart disease in 52-62-year-old women: the Kuopio Osteoporosis Risk Factor and Prevention Study. Maturitas 2009;63:73-8.

38 Al-Delaimy WK, Rimm E, Willett WC, Stampfer MJ, Hu FB. A prospective study of calcium intake from diet and supplements and risk of ischemic heart disease among men. Am J Clin Nutr 2003;77:814-8.

39 Ascherio A, Rimm EB, Hernan MA, Giovannucci EL, Kawachi I, Stampfer MJ, et al. Intake of potassium, magnesium, calcium, and fiber and risk of stroke among US men. Circulation 1998;98:1198-204.

40 Van der Vijver LP, van der Waal MA, Weterings KG, Dekker JM, Schouten EG, Kok FJ. Calcium intake and 28-year cardiovascular and coronary heart disease mortality in Dutch civil servants. Int J Epidemiol 1992;21:36-9.

41 Hsia J, Heiss G, Ren H, Allison M, Dolan NC, Greenland P, et al. Calcium/vitamin D supplementation and cardiovascular events. Circulation 2007;115:846-54

42 Wang TJ, Pencina MJ, Booth SL, Jacques PF, Ingelsson E, Lanier K, et al. Vitamin $D$ deficiency and risk of cardiovascular disease. Circulation 2008;117:503-11.

43 Jackson RD, LaCroix AZ, Gass M, Wallace RB, Robbins J, Lewis CE, et al. Calcium plus vitamin D supplementation and the risk of fractures. N Engl/ Med 2006;354:669-83.

44 Wactawski-Wende J, Kotchen JM, Anderson GL, Assaf AR, Brunner RL, O'Sullivan MJ, et al. Calcium plus vitamin D supplementation and the risk of colorectal cancer. N Engl/ Med 2006;354:684-96.

45 Lappe JM, Davies KM, Travers-Gustafson D, Heaney RP. Vitamin D status in a rural postmenopausal female population. J Am Coll Nutr 2006;25:395-402.

46 Reid IR, Bolland MJ, Grey A. Does calcium supplementation increase cardiovascular risk? Clin Endocrinol (Oxf) 2010; published online 23 Feb.

47 Reid IR, Schooler BA, Hannan SF, Ibbertson HK. The acute biochemical effects of four proprietary calcium preparations. Aust NZ J Med 1986;16:193-7.

48 Lind L, Skarfors E, Berglund L, Lithell H, Ljunghall S. Serum calcium: a new, independent, prospective risk factor for myocardial infarction in middle-aged men followed for 18 years. J Clin Epidemiol 1997; 50:967-73.

49 Jorde R, Sundsfjord J, Fitzgerald P, Bonaa KH. Serum calcium and cardiovascular risk factors and diseases: the Tromso study. Hypertension 1999;34:484-90.

50 Foley RN, Collins AJ, Ishani A, Kalra PA. Calcium-phosphate levels and cardiovascular disease in community-dwelling adults: the Atherosclerosis Risk in Communities (ARIC) Study. Am Heart) 2008;156:556-63.

51 Nilsson IL, Yin L, Lundgren E, Rastad J, Ekbom A. Clinical presentation of primary hyperparathyroidism in Europe-nationwide cohort analysis on mortality from nonmalignant causes. J Bone Miner Res 2002;17(suppl 2):N68-74S.

52 Vestergaard P, Mollerup CL, Frokjaer VG, Christiansen P, Blichert-Toft M, Mosekilde L. Cardiovascular events before and after surgery for primary hyperparathyroidism. World I Surg 2003;27:216-22.

53 Green JH, Booth C, Bunning R. Postprandial metabolic responses to milk enriched with milk calcium are different from responses to milk enriched with calcium carbonate. Asia Pac J Clin Nutr 2003;12:109-19.

54 Pletcher MJ, Tice JA, Pignone M, Browner WS. Using the coronary artery calcium score to predict coronary heart disease events: a systematic review and meta-analysis. Arch Int Med 2004:164:1285-92.

55 Demer LL. A skeleton in the atherosclerosis closet. Circulation 1995;92:2029-32.

56 Avenell A, Gillespie W], Gillespie LD, O’Connell D. Vitamin D and vitamin $D$ analogues for preventing fractures associated with involutional and post-menopausal osteoporosis. Cochrane Database Syst Rev 2009;2:CD000227.

57 DIPART (Vitamin D Individual Patient Analysis of Randomized Trials) Group. Patient level pooled analysis of 68500 patients from seven major vitamin D fracture trials in US and Europe. BMJ 2010;340:b5463.

58 Reid IR, Bolland MJ, Grey A. Effect of calcium supplementation on hip fractures. Osteoporos Int 2008;19:1119-23.

Accepted: 21 May 2010 